\title{
Impact of Medical Assistants as Health Coaches
}

\author{
Tessa Robrberg, MD, Resident Representative, Editorial Advisory Board \\ Ann Fam Med 2015;13(2):iii. doi:10.1370/afm.1767.
}

$\mathrm{T}$ The Annals of Family Medicine encourages readers to develop a learning community of those seeking to improve health care and health through enhanced primary care. You can participate by conducting a RADICAL journal club and sharing the results of your discussions in the Annals online discussion for the featured articles. RADICAL is an acronym for Read, Ask, Discuss, Inquire, Collaborate, Act, and Learn. The word radical also indicates the need to engage diverse participants in thinking critically about important issues affecting primary care and then acting on those discussions. ${ }^{1}$

\section{HOW IT WORKS}

In each issue, the Annals selects an article or articles and provides discussion tips and questions. We encourage you to take a RADICAL approach to these materials and to post a summary of your conversation in our online discussion. (Open the article online and click on "TRACK Comments: Submit a response.") You can find discussion questions and more information online at: http://www.AnnFamMed.org/site/AJC/.

\section{CURRENT SELECTION}

\section{Article for Discussion}

Willard-Grace R, Chen EH, Hessler D, et al. Health coaching by medical assistants to improve control of diabetes, hypertension, and hyperlipidemia in low-income patients: a randomized controlled trial. Ann Fam Med. 2015;13(2):130-138.

\section{Discussion Tips}

This article investigates the impact of in-clinic health coaching by medical assistants using data from a randomized controlled trial of low-income patients in safety net primary care clinics in San Francisco. The study considers the effectiveness of this model on control of hemoglobin A1c, systolic blood pressure, and LDL cholesterol and explores potential factors in implementation.

\section{Discussion Questions}

- What question is asked by this study and why does it matter?

- How does this study advance beyond previous research and clinical practice on this topic?

- How strong is the study design for answering the question?

- How well does the study follow the CONSORT guidelines? (www.consort-statement.org)

- To what degree can the findings be accounted for by:

1. How patients were selected, excluded, or lost to follow-up?

2. How the main variables were measured?

3. Confounding (false attribution of causality because 2 variables discovered to be associated actually are associated with a 3rd factor)?

4. Chance?

5. How the findings were interpreted?

6. "Contamination" between intervention and control groups? How might this possibility be avoided in the study design?

-What are the main study findings?

- How comparable is the study sample to similar patients in your practice? What is your judgment about the transportability of the findings?

- What contextual factors are important for interpreting the findings? How strong are the methods for assessing contextual factors affecting implementation?

- How might this study change your practice? Policy? Education? Research?

-What might be the financial impact of implementing a similar model? At what level do the costs accrue? At what level are the benefits likely to appear over time? (eg patient, practice, health care system, community?)

-What other in-clinic interventions may lead to similar results?

- Who the constituencies are for the findings, and how they might be engaged in interpreting or using the findings?

- What are the next steps in interpreting or applying the findings?

- What researchable questions remain?

\section{References}

1. Stange KC, Miller WL, McLellan LA, et al. Annals Journal Club: It's time to get RADICAL. Ann Fam Med. 2006;4(3):196-197. http:// annfammed.org/cgi/content/full/4/3/196. 